\title{
Leyes migratorias y representaciones sociales: el caso argentino
}

\author{
Migration laws and social representations: the Argentinian case
}

Anahí González

Universidad de Buenos Aires

Becaria CONICET

anahipgonzalez@gmail.com

Romina Tavernelli

Universidad de Buenos Aires

Instituto de Investigaciones Gino Germani

rtavernelli@sociales.uba.ar

\begin{abstract}
Resumen
El objetivo del presente artículo es indagar sobre las tramas discursivas existentes acerca de los migrantes internacionales a partir del análisis del caso argentino. Con este propósito, se examinan las leyes migratorias y el reciente Decreto de Necesidad y Urgencia 70/2017, encargados de la gestión sobre la cuestión migratoria en el país, articulándolos con los datos producidos en el marco de una investigación, en la que se realizaron entrevistas a miembros del poder judicial del Área Metropolitana de Buenos Aires. Ambos materiales, los corpus normativos y los discursos de los entrevistados, son abordados con estrategias de análisis de carácter cualitativo, empleando para ello el programa Atlas Ti. Se desprende del análisis que las representaciones sociales son construcciones marcadamente más complejas y duraderas que la simple voluntad de los gobiernos y que a pesar de los distintos cambios en la normativa, perviven percepciones acerca del migrante que lo configuran como un sujeto amenazante. Puede concluirse que tales impresiones permanecen en estado latente o pueden resurgir según la coyuntura política resistiendo toda evidencia en sentido contrario.
\end{abstract}

Palabras claves: migraciones internacionales, representación social, leyes migratorias

\begin{abstract}
This article enquires into the discursive narratives regarding migrants, taking as its starting point an analysis of the Argentinian case. It examines Argentina's policies about migration and discusses them with the data produced during this research. Data includes interviews with more than fifty persons who worked at the Justice Department in Buenos Aires's Metropolitan Area. Both materials-- the migration laws and these interviews-- are subjected to qualitative analysis, by using Atlas.ti software. It is clear from the analysis that the complexity of social representations lie beyond the government's will. Thus, despite changes in regulations, perceptions about migrants as threatening subjects persist. Such impressions about the "other" remain in a latent state or may be more visible and explicit according to the political context, sometimes in opposition to all the evidence in the contrary.
\end{abstract}

Key words: international migration, social representations, migration laws 


\section{Introducción}

A pesar del protagonismo del que goza la problemática migratoria en la actualidad, lo que condujo a no pocos autores a establecer que nos encontramos en la era de las migraciones (Velasco, 2016), resulta evidente -donde se lo observe- que dicho fenómeno no se da sin contradicciones. Las migraciones son, sin duda, un fenómeno global que acontece en un mundo desigual que restringe, limita y circunscribe dicho movimiento, determinando así quiénes pueden migrar (en qué condiciones) y quiénes no.

Es en tal sentido que las migraciones son selectivas tanto de sus poblaciones como de los destinos y procedencias. En este contexto, la principal contradicción que subyace parece ser entonces que mientras

...el capital, los medios de comunicación y los bienes simbólicos parecen atravesar el mundo sinningún tipo de barrera, $[\ldots]$ los inmigrantes se enfrentan a fronteras geopolíticas y simbólicas que establecen y controlan quién puede entrar y circular en los territorios nacionales, y cómo ellos son nombrados de uno u otro lado de los límites de los Estados nacionales (FeldmanBianco, 2011:15).

En este artículo nos aproximamos al análisis de las migraciones desde una perspectiva que asume una "mirada bifocal que permite organizar analíticamente las relaciones entre las políticas de la enunciación, las representaciones sociales y la praxis política" (Feldman-Bianco, 2011: 18).

Para la reflexión sobre la praxis política, proponemos observar críticamente las tres leyes migratorias que a lo largo de la historia argentina, regularon el ingreso, permanencia y -en ocasiones- la expulsión de los migrantes, y el reciente Decreto de Necesidad y Urgencia, firmado por el Poder Ejecutivo Nacional en enero de 2017.
Si bien han existido, en el tiempo, otros instrumentos de gestión política que tuvieron como objetivo regular la presencia migrante en la Argentina, tales como decretos, resoluciones, disposiciones transitorias y reglamentaciones a las leyes ya existentes -como el caso de la Reglamentación del año 1987, a la Ley de Inmigración puesta en práctica durante la dictadurasólo tres de tales instrumentos han tomado la forma de Ley.

No obstante, cabe destacar que no pretendemos aquí analizar las leyes migratorias desde una perspectiva hermenéutica sino, más bien, rastrear qué cambió y qué pervive en relación a la construcción, desde el Estado, de una imagen acerca del inmigrante/ extranjero. Asumimos que tales imágenes forman parte de las lógicas discursivas subyacentes de nuestros entrevistados al punto de constituirse como representaciones acerca de la otredad compartidas socialmente. En suma, reflexionamos en torno a la articulacion de ambos "discursos", el de las leyes y aquel que se produjo en el marco de nuestro trabajo de campo, rastreando allí rupturas y continuidades. Es este enfoque el que nos aleja de otros análisis (Novick, 2008 ; 2005) que asumen una perspectiva comparativa de las mismas leyes los cuales resultan una referencia insoslayable si se quiere abordar los corpus jurídicos en tal sentido.

Específicamente, las leyes adquieren relevancia para nuestro análisis dado que han sido siempre herramientas de las que se valieron los sectores dominantes para convertir a la migración en objeto de regulación, control y dominación. En este sentido, ellas tuvieron y tienen un doble propósito: por un lado, crear al inmigrante como un tipo especial de "otro" (al que hay que controlar mediante la ley), y por el otro, fijar tal representación en la propia ciudadanía nacional, a través de la dominación simbólica. Sin dudas, el efecto que tal conjunción produce es percibir a ese "otro" migrante como a un extraño, de modo tal que 
la ley debe ejercer sobre él su poder de vigilancia. En definitiva, la ley convierte al migrante en un problema sobre el que se debe gestionar.

Consecuentemente, siguiendo a Crosby (2006: 3), afirmamos que

las políticas de migración reflejan quiénes somos como nación y ciudadanos, porque ellas establecen los límites entre 'nosotros' y 'ellos', quiénes pueden pertenecer y quiénes no pueden. Estas fronteras de pertenencia se están convirtiendo cada vez más en las murallas de una fortaleza que separan a los privilegiados y poderosos de los más vulnerables y marginados.

En definitiva, y tal como ya hemos planteado, interpretamos que el Derecho es más que un instrumento de gestión de la otredad, pues también contribuye a la creación representacional del inmigrante como "otro", como un extraño, sobre el cual el Estado debe procurarse una legislación.

En vinculación con tal construcción social, nos acercamos a la cuestión migratoria y sus sujetos, desde las representaciones sociales que se construyen en el seno de la sociedad receptora, en torno a las migraciones.

Dichas representaciones son parte de un proceso de construcción de la otredad colmado por una multiplicidad de miradas, que frecuentemente personifica más a quien las construye que a quien es construido por ellas. El pensar y el hacer en relación al "otro" forman parte de un sistema perceptivo y conceptual, compartido socialmente, en el que intervienen las impresiones que acerca de la otredad, se construyen en el marco de distintas instituciones que, en definitiva, administran su presencia.

Finalmente, es a través del análisis de discursos sociales que podemos adentrarnos en las representaciones sociales que desde la sociedad receptora se construyen y circulan acerca de los migrantes. Las políticas de la enunciación comprenden las representaciones sociales y su expresión en las leyes migratorias que se conforman como el discurso oficial frente a la migración.

Teniendo en cuenta lo dicho anteriormente, en el artículo se presenta, en primer lugar, el abordaje metodológico utilizado a lo largo de la investigación, de la que se desprenden los datos que aquí se exponen.

A continuación, recorremos las tres leyes migratorias y el Decreto de Necesidad y Urgencia dictado por el actual gobierno nacional y que modifica sustancialmente a la última ley de migraciones. Con ello aspiramos a rastrear en el corpus legal que rigió históricamente la cuestión migratoria en la Argentina, la construcción de la imagen del sujeto migrante, que se propuso desde el Estadonación argentino. Las continuidades y rupturas de dicha representación son abordadas comparativamente de modo de reflejar un camino sinuoso en el que la relación planteada para con los migrantes, no siempre fue en favor de su integración.

Articulamos dichas leyes con citas extraídas de las entrevistas realizadas en el trabajo de campo llevado a cabo durante la investigación, como una forma de dar cuenta del anclaje que aquellas tienen en las representaciones sociales expresadas discursivamente.

Finalmente, el artículo, en un momento histórico marcadoporel aumento de expresiones discriminatorias, se presenta como un escrito de gran actualidad que aspira a contribuir a la reflexión acerca de cómo, desde los marcos normativos y legales, se construye una representación social acerca de los migrantes que, en función de los distintos contextos, colabora o dificulta el vínculo entre quienes llegan y los sujetos de la sociedad de arribo. 


\section{Apartado metodológico}

En el artículo se incluyen fragmentos de entrevistas realizadas en el marco de una investigación[1] de gran envergadura en la cual se indagó acerca de las representaciones sociales que miembros del Poder Judicial del Área Metropolitana de Buenos Aires (que incluye a la Ciudad Autónoma de Buenos Aires, en adelante CABA, y el Gran Buenos Aires, en adelante GBA) construyen sobre los migrantes externos. Es decir, la unidad de recolección de información fueron los miembros nativos de dicha institución; la misma ha sido el universo de estudio porque consideramos que es uno de los espacios en los que el Estado administra la diversidad y donde se establecen los castigos a los delitos e ilegalismos así como también se reconocen o desconocen derechos.

Partimos de la definición de representaciones sociales de Jodelet (1986: 473) quien afirma que las representaciones sociales refieren a la forma sobre "cómo nosotros, sujetos sociales, aprehendemos los acontecimientos de la vida diaria, las características de nuestro medio ambiente, las informaciones que en él circulan, a las personas de nuestro entorno próximo o lejano". Pero, además, coincidimos con la autora en que éstas adquieren un valor performativo, dado que son "modalidades de pensamiento práctico orientados hacia la comunicación, la comprensión y el dominio del entorno social, material e ideal" (Jodelet, 1986: 472). En consecuencia, las representaciones sociales se vuelven un conocimiento pragmático que sirve para proyectar las acciones de los sujetos y dominar su entorno social. En relación con la propuesta de análisis en este artículo, entendemos que la construcción del otro a partir de lo que percibimos de él, apela a construcciones sociales sedimentadas históricamente como lo son, en nuestro caso, los instrumentos jurídicos que legislaron sobre la migración en nuestro país.

La perspectiva asumida para el trabajo de campo fue cualitativa, efectuándose 52 entrevistas bajo la técnica de entrevistas en profundidad. Dicho número resultó de la implementación metodológica conocida como "saturación teórica de la muestra", definida por Strauss como aquel momento en que el crecimiento muestral no contribuye a nada nuevo al interior de las categorías de análisis (Strauss y Corbin, 2002). Las entrevistas fueron grabadas y posteriormente desgrabadas de modo textual para su análisis. Dado que se utilizó una misma guía de pautas para todas las entrevistas, la información pudo ser analizada bajo el "método de comparación constante". (Strauss y Corbin, 2002) Con este fin, las desgrabaciones fueron incorporadas a una matriz de datos a través del programa ATLAS. ti y analizadas a partir de la metodología de Strauss y Corbin consistente en las etapas de codificación abierta (procurando estimular el descubrimiento de categorías, propiedades y dimensiones de análisis) y codificación selectiva (con el fin de reducir las categorías).

En relación a la sistematización de las leyes y del DNU, se hizo lo propio empleando este mismo programa de procesamiento de datos. Todos los documentos fueron incluidos en una Unidad Hermenéutica y analizados a partir de criterios cualitativos, siguiendo también la Teoría Fundamentada de Strauss y Corbin (2002) [2].

\section{La construcción del extranjero a través de las tres leyes migratorias argentinas.}

La modificación de los patrones migratorios a lo largo de la historia argentina, afectó no sólo la dirección de sus flujos sino también su composición. Los Censos Nacionales de Población y Vivienda realizados en el país, muestran notoriamente dichas fluctuaciones, pero éstas son igualmente evidentes cuando se analiza la población objetivo de las tres leyes migratorias que legislaron dicha cuestión en la Argentina. 
En cada una de ellas es ostensible el sujeto (migrante, extranjero) al que se interpela y con ello la construcción del tipo de migrante que, desde el Estado, se esperó que llegara. Analizando comparativamente los corpus normativos, puede notarse cómo dicho sujeto fue modificándose según el contexto histórico de sanción de cada uno de ellos. Sin la pretensión de un análisis hermenéutico de las leyes, su observación crítica ayuda a reconstruir la imagen del "inmigrante" que buscó -y aún busca- erigir el Estado en cada contexto socio-histórico. Esta indagación comparativa permite detectar lo que quedó y lo que cambió en cada una de ellas en relación a la construcción representacional del inmigrante-extranjero. Eso es, fundamentalmente, lo que presentamos a continuación.

\subsection{La primera ley de migraciones en Argentina}

A mediados del siglo XIX, el proyecto de país de las elites dirigentes argentinas requería de abundante mano de obra para la consolidación, crecimiento y desarrollo de una economía que se fundaba en un modelo agroexportador.

El capital, ya concentrado en los países industrializados del norte de Europa, se dirige por entonces a países no europeos de ultramar, resultando que capitales y personas se mueven en la misma dirección. Como consecuencia de ello, a partir de 1870, comienzan a llegar masivamente a la Argentina migrantes provenientes de los sectores de la periferia económica europea. La necesidad de trabajadores -inicialmente para el campo y, más adelante, para el incipiente desarrollo industrial- así como el propósito de poblar el extenso territorio nacional, fueron los pilares de la convocatoria lanzada por el Estado nacional, que llamó a emprender el viaje a los ciudadanos del mundo que quisieran poblar y trabajar el suelo argentino.
Eneste contexto,en 1876, se sancionóbajo la presidencia de Nicolás Avellaneda, la Ley 817 de Inmigración y Colonización, que administró la política migratoria por más de cien años. Visto retrospectivamente, puede considerarse a este hecho como un hito histórico en sí mismo dado que, por primera vez, se abordaron las migraciones como una cuestión de Estado y, con ello, se inauguró la construcción de la figura del sujeto inmigrante que se consideró "deseable".

La ley Avellaneda se fundó en la certeza que la inmigración externa contribuiría al crecimiento y desarrollo de la economía, así como a asegurar la extensión de la autoridad del Estado (y el gobierno nacional) a la totalidad del territorio. Evocada como una ley de "puertas abiertas", sus artículos están colmados de verbos tales como: "fomentar", "proveer", "facilitar", "recibir", "alojar".

En el marco de la ley y con el fin de atraer trabajadores, se abrieron agencias oficiales en el exterior (fundamentalmente en Europa) que buscaron "proponer para fomentar" y "vigorizar el desarrollo de la propaganda continua a favor de la inmigración a la Argentina". De este modo, el Estado se colocó al frente de esta promoción con acciones tales como; "realizar contratos con empresas de transporte", "recibir y ubicar a los inmigrantes", "cubrir los gastos de los inmigrantes los primeros cinco días después de su arribo" y hasta cubrió el pago de pasajes en la movilización interna de los inmigrantes hacia las tierras a colonizar. Asimismo, creó el fondo nacional para la inmigración con el que se construyeron "casas de alojo" en distintas jurisdicciones.

Decíamos más arriba que esta ley resulta interesante de analizar dado que con ella el Estado definió, por primera vez qué es un inmigrante y con ello, a quiénes esperaba recibir. Definía la ley: "repútase inmigrante para los efectos de esta ley a todo extranjero jornalero, artesano, industrial, agricultor o profesor que, siendo 
menor de sesenta años, y acreditando su moral y sus actitudes, llegase a la República para establecerse en ella" (Capítulo V, artículo 12). Desde el inicio, la figura del inmigrante estuvo fuertemente asociada a la del trabajador, motivo por el cual, a su llegada, se registraban sus conocimientos, aptitudes y si sabía o no leer.

Cabe destacar que la representación acerca del migrante de origen europeo como alguien que contribuye al engrandecimiento de la nación, aún pervive en las representaciones sociales de la sociedad argentina. Todavía hoy, los migrantes europeos son percibidos como aquellos sujetos que venían a trabajar, a quedarse y formar su familia. Tales representaciones estuvieron muy presentes en el trabajo de campo que realizamos en instituciones judiciales, como puede verse en las citas que siguen:

- Lo que pasa es que hay dos... creo que hay como dos momentos dentro de la historia argentina en cuanto a las fuentes migratorias. La que viene de Europa con la Guerra Mundial y quizás ahora, la más actual, que son los de los países limítrofes. Entonces, eso creo que tiene mucho que ver. La que viene de Europa, por lo general, primero se caracterizó por forjar el país y era un grupo trabajador, que serían lo que hoy somos los residuos de la clase media y algunos, alta. Y la otra etapa migratoria, que será de 15 años a esta altura, que es la de los países limítrofes, que ahí sí se caracteriza... tiene mucho que ver también con el tema de que están por debajo de la línea de pobreza muchos de ellos ¿no? (Secretaria. Juzgado de Garantías N². GBA).

Bueno, yo creo que esto tiene mucho que ver con las características propias de las migraciones ¿No es cierto? Creo que es un hecho que las migraciones hace muchos años que han venido al país se relacionaba con gente de trabajo ¿No es cierto? Muchos de nuestros abuelos o bisabuelos tienen que ver con eso. Las migraciones más actuales... bueno, habría que ver los índices y estadísticas que realizan algunos organismos, como el ministerio público fiscal, en cuanto a esa clasificación de delitos cometidos en muchas ocasiones por personas que vienen de otros países, especialmente los limítrofes. Esto se ve a diario en las causas, es un dato objetivo (Juez. Cámara Nacional de Apelaciones en lo Criminal y Correccional).

La importancia otorgada al hecho que el migrante se radicase, se arraigase en el país, también estuvo contemplada en la ley, en especial cuando ésta afirmaba que el inmigrante no podía utilizar las franquicias acordadas para dirigirse de tránsito por el territorio de la Argentina como país de paso a una nación extraña. (Capítulo 9, artículo 54).

En efecto, nuevamente en la actualidad, esta cuestión aparece resignificada en las representaciones sociales, y es asumida como prueba de la lealtad del migrante para con la sociedad receptora. La representación acerca del "buen migrante" de origen europeo, que venía a quedarse en nuestro país para hacer su vida aquí, se construye todavía en contraposición al "mal migrante" que, viniendo de países limítrofes, no quiere quedarse sino sólo enviarle el dinero que gana acá, a su familia que queda en su país de origen, tal como se ve en el ejemplo que sigue:

- El inmigrante antes venía a construir todo, de cero, de vuelta. Venía a construir su casa, su familia... El inmigrante, hoy en día, no viene a instalarse. Viene a instalarse para trabajar, pero sigue teniendo un contacto muy fuerte con su lugar de origen. Y entonces, viene generalmente a buscar un trabajo de posibilidades económicas...muchas veces para mandar plata para allá... Pero no viene con esa perspectiva de... "bueno, me instalo acá y voy 
a construir mi vida acá, para siempre". Quizá la inmigración anterior cortaba mucho más fuerte el vínculo. Creo que eso cambia...el inmigrante de hoy sigue muy... mucho más vinculado a su país de origen, muchas veces viene por una cuestión laboral, o de oportunidades médicas, y nada más" (Prosecretario. Ministerio Público Fiscal. CABA).

La ley interpela a un tipo de sujeto y define, en ese ejerciciountipodeinmigrante deseable.Históricamente, el privilegio otorgado a aquellos que provenían de Europa es evidente, explícito y está presente no sólo en la letra de la ley que aquí analizamos sino también en la de la Constitución Nacional, sancionada poco más de veinte años antes.

En el artículo 25 de la Constitución Nacional aún hoy puede leerse:

El Gobierno federal fomentará la inmigración europea; y no podrá restringir, limitar ni gravar con impuesto alguno la entrada en el territorio argentino de los extranjeros que traigan por objeto labrar la tierra, mejorar las industrias, e introducir y enseñar las ciencias y las artes.

Resulta evidente, ya desde la primera ley referente a las migraciones, cómo las fronteras fueron desigualmente percibidas y gestionadas por parte del Estado-nación argentino, que privilegió siempre a algunos grupos nacionales por sobre otros y construyó una expectativa sobre qué tipo de inmigrante esperó que llegara. En dicha expectativa, subyacía, sin dudas, una jerarquización de los orígenes nacionales y con ello una clasificación encubierta acerca de los sujetos, que lo habilitó a "seleccionar" qué migrantes serían bienvenidos y, como contraparte, quiénes no.

En definitiva, las fronteras nacionales no estuvieron igualmente abiertas para todos los sujetos, dependiendo esta condicionalidad del origen nacional del migrante.
Sin embargo, contrariamente a lo que se supuso, las migraciones llegadas entre mediados del siglo XIX y primera mitad del siglo $\mathrm{XX}$, no lo hicieron de todos los países de Europa o, como se esperaba, de la Europa industrializada, sino que arribaron, mayoritariamente, de la Europa Mediterránea predominantemente rural, lo cual ya configuró una primera crisis de expectativas.

Si bien existe hoy en día la percepción social que considera que las migraciones que llegaron en el período que aquí referimos fueron bien recibidas, numerosos documentos, así como otros instrumentos legislativos, tales como la Ley de Residencia[3] (1902) y la Ley de Defensa Social[4] (1910), muestran que tal idea es parte de un imaginario construido desde la actualidad; en tal sentido, las percepciones de hoy dan cuenta de un desfasaje representacional si se considera cómo fueron recibidos los migrantes del ayer.

\subsection{El control migratorio a partir de la dictadura militar.}

Más de cien años después, la cuestión migratoria volvió a ser objeto de examen. En el contexto latinoamericano de dictaduras militares en el poder, el régimen de Videla en Argentina deroga en 1981 la ley hasta entonces vigente y elabora un nuevo instrumento de regulación de las migraciones. A pesar de no haber atravesado la instancia legislativa, dicho proyecto fue denominado "Ley General de Migraciones y de Fomento de la Inmigración", abarcando en un único texto todas las cuestiones vinculadas a la migración y la extranjería.

Con la Doctrina de la Seguridad Nacional como sustrato, son numerosos los cambios incorporados en relación a la percepción del "inmigrante". El más llamativo es el que se relaciona con la forma de nominarlos. Los migrantes pasan de ser "inmigrantes" (en la mayoría de los artículos de la ley anterior) a ser considerados "extranjeros". Así, mientras en el primer caso el prefijo 
“in" señala a alguien que "está en", un adentro; en el segundo caso, el prefijo "ex" denota exterioridad, "estar fuera de", más allá del tiempo y del espacio[5] .

Al mismo tiempo, se establecieron "categorías de extranjeros" quienes, según los tiempos de permanencia en el país, fueron clasificados en: "permanentes", "temporarios" y "transitorios", lo cual expuso la voluntad por parte del Estado de colocar a los sujetos en condición de tránsito desestimando así la posibilidad de asentamiento. Análogamente se propusieron una variedad de cambios en relación a los verbos que recorren sus artículos.

El primero de ellos es que se plasmaron en formas impersonales: "créase", "se declara", entre otras, retirándose así el Estado como actor promotor de la migración.

El segundo refiere a la carga valorativa de éstos. Si en la Ley Avellaneda buscaban fomentar, promover, etc., en la ley de 1981 los verbos tendieron a desalentar el traslado y a introducir la noción de un Estado que vigila. Valen como ejemplos los verbos que aparecen a lo largo de la ley, tales como, "controlar", "restringir", "multar", "sancionar" o "rehusar la admisión".

Resulta destacable que, desde los primeros artículos, queda manifiesta la intención restrictiva en relación a los movimientos migratorios.

La primera de ellas ordena que el Poder Ejecutivo promueve la inmigración de extranjeros de acuerdo a las necesidades poblacionales, de modo que la migración ya no es considerada como un libre movimiento de personas.

La segunda restricción está fundada en las características asignables a los inmigrantes, ya que el Poder Ejecutivo alentaría la inmigración de aquellos sujetos cuyas características culturales permitieran la adecuada integración en la sociedad argentina (Título 1, artículo 2).
También se estableció una restricción en relación a los posibles lugares de asentamiento, dado que el Poder Ejecutivo determinaba "las zonas del interior del país que se consideren prioritarias para el poblamiento y adoptará las medidas necesarias para promoverlo" (Título 1, capítulo 3), entendiéndose así que el Estado podía reubicar a los inmigrantes en función de las "necesidades poblacionales" que este estableciera.

Cabe enfatizar que a lo largo de toda la normativa, aparece subyacente la construcción del inmigrante como un sujeto peligroso al que se debía controlar, y con tal objetivo, la creación de la Policía Migratoria, en el marco de la ley, viene a cumplir dicha función. Como corolario de esta construcción del migrante como una amenaza al orden social, se incluyó por primera vez la equiparación de la falta de documentación con el estatus de ilegalidad, convirtiendo así al inmigrante en un delincuente. Por extensión, en varios artículos se promovió la delación entre ciudadanos (sujetos con o sin función pública) como forma de gestionar la inmigración. Las autoridades escolares, sanitarias o posibles empleadores, al conocer el carácter de "ilegal" del inmigrante debían denunciarlo a las autoridades nacionales. En este sentido, se destinaron dos capítulos completos a definir a los ilegales y a qué hacer con ellos (la expulsión sería para todos, el destino último). Así, apelando a estrictas razones de seguridad, las autoridades podían disponer la expulsión y prohibición de reingreso de los sujetos considerados sospechosos.

Un dato llamativo surge al comparar el artículo 42 en ambas leyes. Mientras en la primera -en el marco de las condiciones de admisión- se decide la construcción de "casas de alojamiento" para los inmigrantes, en la segunda -en el marco de la fijación de los criterios para la expulsión- se establecen los lugares de detención de los extranjeros. 
La representación de los extranjeros como sujetos peligrosos a los que se debe vigilar, pervive a través de la ley por todo el periodo de transición y primeros gobiernos democráticos hasta que en el año 2003 se sanciona finalmente la "nueva ley de migraciones".

\subsection{La Ley de Migraciones 25.871, una ley de la democracia.}

La Ley 25871 nace en una América Latina con democracias consolidadas y con fuerte voluntad de reforzar procesos de integración regional. Así, en el marco de un nuevo impulso al MERCOSUR, el sujeto subyacente de esta ley es el migrante latinoamericano. Sancionada en marzo de 2003 y reglamentada recién 7 años después, lo cual se vincula con los distintos intereses en pugna que ella involucraba, resultaba de igual manera un dato alentador que, tras décadas en que el poder legislativo no se pronunciara acerca de qué normativa migratoria se debía adoptar en un escenario internacional en el que la profundización de las contradicciones económicas y políticas continuaban evidenciando la relevancia y vigencia de la cuestión migratoria, se iniciara un camino hacia la deconstrucción de lo estipulado por la "Ley Videla".

En líneas generales, sin duda, lo más destacable de la normativa ha sido que concibe a la migración como un derecho humano, afirmando que "el derecho a la migración es esencial e inalienable de la persona y la República Argentina, lo garantiza sobre la base de los principios de igualdad y universalidad" (Título 1, Capítulo I, artículo 4). Se percibe un cambio de percepción en relación al migrante, en general, y al latinoamericano, en particular. Se recupera el concepto de inmigrante al que, ya en el artículo 2, se lo define como quien desee ingresar, transitar, residir o establecerse en el país. No se trata de recuperar sólo el prefijo sino de concebir a la persona que llegaba como alguien que contribuye al enriquecimiento y fortalecimiento del tejido cultural y social del país (Capítulo 1, artículo 2, inciso c). En este sentido, el aporte del inmigrante ya no se reduce a su contribución como fuerza de trabajo, sino que es recibido valorando, además, toda su riqueza y dimensión como sujeto. Si recorremos el resto del texto de la ley hay otros puntos también importantes a resaltar.

En relación al Estado, éste recupera su rol protagónico en la promoción de las migraciones (el represivo nunca lo había abandonado) pues la mayoría de artículos se inician invocándolo. Con él se vuelve a apelar a verbos como "contribuir", "garantizar", "promover", entre otros. Adicionalmente, es muy destacable que éstos vienen ahora a equiparar derechos, reconociendo pactos y principios internacionales sobre los cuales Argentina había asumido su compromiso. Así, afirma el artículo 6 del primer capítulo, el Estado asegurará el acceso igualitario a los inmigrantes en las mismas condiciones de protección, amparo y derechos de los que gozan los nacionales, estipulando que en ningún caso la irregularidad migratoria podrá impedir el acceso a derechos. Tal equiparación es inédita y configura un salto cualitativo no sólo en materia de derechos sino también en la forma de concebir a quien viene a habitar la nación, es decir, como un sujeto de derecho más allá de su origen nacional.

Como decíamos, el rol del Estado -como regulador de los flujos migratorios- no ha sido abandonado en ningún momento de nuestra historia como Nación. El caso de la Ley 25871 no es una excepción de ello, ya que también se hace presente en la regulación de la entrada y permanencia[6] de los extranjeros al territorio nacional. El título II reúne estas disposiciones en una serie de artículos bajo el título "de la admisión de extranjeros a la República Argentina y sus excepciones."

En este sentido, la Ley número 25871 marca una diferencia con lo normado hasta el momento por la Ley Videla que, como hemos dicho ya, otorgaba a la Dirección Nacional de Migraciones (en adelante, 
DNM) la potestad de decidir acerca de la permanencia y expulsiones de los migrantes. Esta situación suponía la indefensión de los extranjeros y la negación de su condición de sujeto de derechos. Con la sanción de la Ley en el 2003 se establecen una serie de derechos básicos en relación a las garantías del debido proceso en casos de expulsiones, instituyéndose además una serie de funciones del Poder Judicial ajeno, hasta el momento, a este tipo de procedimientos.

Específicamente, los artículos 5 y 6 de la ley hacen referencia a la obligación del estado de establecer las garantías que asegurarán el acceso a los derechos de los migrantes que la normativa formalmente consagra. Asimismo, en su artículo 61 la Ley establece que toda decisión de expulsión por parte de la Dirección Nacional de Migraciones tendrá "efecto suspensivo". Es decir, que se garantiza el derecho de interponer los recursos pertinentes: Recursos de Reconsideración, Jerárquico o Alzada o recursiva judicial. De esta manera, una vez notificado, el migrante tiene el derecho de interponer recursos administrativos con el fin de pedir una revocación de la decisión tomada por la DNM. Si la decisión de expulsión es confirmada el migrante cuenta con dos opciones: continuar con la vía administrativa (Recurso de Alzada ante el Ministerio del Interior) o proseguir por vía judicial. Respecto a la detención, tras la solicitud hecha por la DNM, aquella debe ser pedida por un juez competente. Así, se suprime la discrecionalidad que podía implicar que un órgano perteneciente a la órbita del Poder Ejecutivo, como lo es la DNM, tomara las decisiones al respecto, incluyéndose una serie de pasos que garantizaban el debido proceso. La expulsión, por regla general, puede ser solicitada una vez que el pedido de expulsión esté firme; sin embargo, cabe señalar que según el artículo 70 de la ley, "cuando las características del caso lo justifiquen”, la DNM o el Ministerio del Interior pueden solicitar la retención del extranjero aunque la orden de expulsión no contara con esa condición.
Al momento de sanción de la ley, las cuestiones referentes al proceso de expulsión recaen en el Fuero Contencioso Administrativo[7] , al tiempo que el Ministerio Público de Defensa[8] (en adelante, MPD) resulta ser el que asume el rol defensor. En el marco de esta disposición, se crea dentro del Ministerio Público de Defensa, el 28 de noviembre de 2008, bajo la resolución DGN $N^{\circ} 1858 / 08$ [9] , la Comisión del Migrante[10] . En sintonía con ello, en la Resolución DGN $N^{\circ} 569 / 11$ se cita que el artículo 86 del decreto (616/2010) reglamentario de la Ley 25.871 dispone que

La DNM, ante el planteo que efectúe un extranjero, dará inmediata intervención al MPD, disponiendo la suspensión de cualquier trámite y de los plazos en curso en las actuaciones administrativas, hasta que el referido Ministerio tome intervención o el interesado reciba la asistencia jurídica necesaria para la salvaguarda de sus intereses.

Que la medida de expulsión tenga carácter suspensivo es una buena señal, al menos formalmente, de la intención estatal de respetar garantías mínimas del debido proceso. En suma, a partir de las especificaciones y la división de tareas dentro de la Defensoría, se comienza a elaborar un entramado burocrático estatal que ya no solo involucra al migrante y a la DNM, sino que incluye como actor novedoso, en casos de expulsión, al sistema judicial, tanto en el área Contencioso Administrativa como en las Defensorías.

Ahora bien, retomando esta doble lectura que hemos propuesto (de la normativa y de las representaciones sociales) la expulsión ha sido una figura que históricamente, como hemos dicho ya, permeó la relación entre los extranjeros y el Estado argentino. Asimismo, se la vinculaba y vincula con un modo de gestión "eficiente" de los flujos migratorios y de lo ilegal. Para graficar esta cuestión, podemos citar el testimonio de una entrevistada y su representación social al respecto. 
Creo que en el 2005 hubo una ley, que se llama Ley Patria Grande[11] , que es como que sensibilizó y atenuó todas las cuestiones vinculadas a los extranjeros. Por ejemplo, en materia contravencional, si una persona tiene un montón de causas por contravenciones, por venta ambulante, por oferta de sexo en la vía pública no hay un mecanismo igual a través del área de migraciones que lleve un control y que haga que lo deporten por esa circunstancia. Entonces en eso es como que uno es crítico porque ve mucha gente que viene y están ilegales y por ahí viven en las villas (...) y no hay un control migratorio que sea categórico (Secretaria. Ministerio Público Fiscal. CABA.).

Esta entrevista realizada en plena vigencia de la Ley 25871 evidencia de qué modo, inclusive en un espacio como el judicial donde la idea de la ley es, al menos formalmente, una guía fundamental, las representaciones sociales y los marcos normativos si bien pueden presentar cierta simetría requieren de marcos temporales diferentes para su transformación o mutación. Asimismo, ello nos permite advertir que si bien un cambio de legislación de carácter más inclusivo siempre es un avance en materia de reconocimiento de derechos de los migrantes, ello no supone en la mayoría de los casos una modificación sustancial en las representaciones e imaginarios que los miembros de las sociedades hospedantes construyen acerca de los extranjeros.

El caso del Decreto de Necesidad y Urgencia sobre el que tratan las páginas que siguen permite demostrar el argumento antes establecido. Así, de modo aún más indudable podemos ver de qué modo los discursos que asocian migración y delito, latentes en la sociedad, se alinean con perspectivas que crean la imagen del migrante como sujeto "peligroso" cuyo fin es el de fundamentar políticas y decisiones estatales excluyentes.

\subsection{Re-construcciones representacionales en la Argentina actual: el caso del DNU 70/17}

A comienzos del año 2017, el Poder Ejecutivo Nacional dictó un Decreto de Necesidad y Urgencia que ha modificado de modo sustancial los avances que se habían alcanzado en materia de reconocimiento de Derechos Humanos de los extranjeros. Asimismo, este decreto ha revivido con intensidad aquella idea del migrante como sujeto peligroso.

En este sentido, dos son las dimensiones importantes a analizar aquí: 1. Las cuestiones de forma. 2. Las cuestiones vinculadas a las representaciones sociales.

\subsubsection{Las cuestiones de forma.}

La modificación de la ley 25871, a través del mecanismo del DNU, reinstala la práctica estatal de reglar los aspectos migratorios sin mediar el tratamiento legislativo. En este sentido, tras la sanción de aquella ley, con la intervención de diversos sectores sociales y políticos y por medio del Congreso Nacional, se vuelven a establecer reglas en relación a los migrantes a través de decisiones del Poder Ejecutivo y nuevamente tendiendo a criminalizar y estigmatizar a los extranjeros. Asimismo, se señala que los artículos modificados a través de un mecanismo como el del Decreto han supuesto afectar la división de poderes. Específicamente, los cambios en los artículos número 29 y 62 de la Ley 25.871 contrarían lo establecido por el artículo 99 de la Constitución Nacional Argentina, el cual determina que el Poder Ejecutivo no puede legislar y que solo bajo circunstancias excepcionales "que hicieran imposible seguir los trámites ordinarios previstos por esta Constitución para la sanción de las leyes, y no se trate de normas que regulen materia penal, tributaria, electoral o de régimen de los partidos 
políticos, podrá dictar decretos por razones de necesidad y urgencia..." (Artículo 99, inc.3).

Se deduce que el DNU 70/17 no respeta lo antedicho en varios aspectos: no hay motivos para entender que existe una situación excepcional o de urgencia que justifique modificar la normativa a través de mecanismos como el de un Decreto; además legisla sobre materia penal al vincular el DNU con la necesidad de asegurar la "seguridad pública", ampliando el instituto de retención preventiva. Al respecto, el artículo 70 también incluye algunas transformaciones importantes: el plazo de retención se aumentó de 15 a 30 días prorrogables por igual tiempo y las excepciones se reducen a quienes tengan hijos argentinos nativos menores o con discapacidad, entre otros cambios.

Resulta imposible analizar completamente todos los cambios introducidos por el Decreto, pero su mención permite darnos una clara idea respecto de qué modo las modificaciones introducidas no resultan progresivas sino restrictivas en materia de reconocimiento de derechos de los extranjeros: se modifica el plazo de la residencia precaria de 180 a 90 días; se incluye en el artículo 29 una reducción de las excepciones por reunificación familiar; se introduce la admisión excepcional a quienes den información a la justicia sobre algún delito de orden migratorio, reinstalando el aspecto delatorio de la ley Videla; se establece que si no se constituye domicilio o no existe tal persona en el mismo se considera que el migrante ha sido notificado en mesa de entradas de la DNM en el término de dos días así como también se autoriza que los medios electrónicos sean válidos para las notificaciones; se establece un endurecimiento en los motivos considerados para la cancelación de la residencia, se incorpora el artículo 62 bis en el que puede leerse que "el otorgamiento de la dispensa establecida en los artículos 29 y 62 de la presente Ley será una facultad exclusiva de la DNM, no pudiendo ser otorgada judicialmente"; se introduce (artículo 69) el "procedimiento especial sumarísimo" en materia de expulsiones eliminándose el recurso de reconsideración y alzada de la ley 25871, que describimos anteriormente. Finalmente, cabe destacar, la supresión del recurso de revisión que el artículo 90 de la ley 25871 originalmente establecía en casos de violaciones del debido proceso, arbitrariedad o bien frente a la existencia de hechos nuevos que pudiesen ser relevantes para el caso.

En el DNU se esgrime que la reducción de los plazos que se especifican en el texto del mismo y que se enmarcan en el "procedimiento sumarísimo" antes mencionado, se debe a que éste duraba "demasiado", desligándose del hecho de que la responsabilidad es del Estado y no del migrante. La "solución" a estas demoras no ha sido mejorar los tiempos de resolución, respetando las garantías del debido proceso, sino establecer tiempos que resultan absurdos. En este sentido, un Informe Técnico[12] generado y publicado por la Defensoría del Pueblo de la Ciudad Autónoma de Buenos Aires plantea que la reducción de los tiempos a tres días hábiles, en que los migrantes podrán presentar los recursos para que se reconsidere su expulsión, hacen imposible cumplir con el procedimiento y los requisitos del mismo, colocando la responsabilidad de dicho proceso en el extranjero ignorando, como dijimos, que es el Estado el que debe impulsar el mismo (Carril, 2017). Coincidentemente, desde el Ministerio Público de Defensa[13] se ha dicho que “...el DNU modificó el mecanismo de manera tal que es el migrante quien debe (1) solicitar la asistencia jurídica gratuita a la DNM y (2) acreditar en forma fehaciente carencia de medios económicos ante la propia DNM." (Cascone, 2017: 40). Ambos aspectos colocan nuevamente a la DNM en un rol central, ya que es esta instancia la que decide si el caso es notificado a la Defensoría. Estos cambios, entre otros, coinciden los expertos, vulneran el acceso a la justicia y el debido proceso. 


\subsubsection{Las cuestiones vinculadas a las representaciones sociales.}

Fundamentalmente es en los argumentos que se presentan bajo el título de los "considerandos" del DNU, donde se evidencian las representaciones sociales que sirven de soporte a las medidas y modificaciones introducidas por el Poder Ejecutivo y que reseñamos con anterioridad. En líneas generales, se vincula a las migraciones con una serie de delitos, re-creando así representaciones sociales acerca de los migrantes que los constituyen como sujetos potencialmente peligrosos y concluyendo que, debido a estos "riesgos", es que se torna necesaria una modificación urgente de una serie de artículos de la Ley número 25.871 .

Que tanto el bien común como el interés general de la sociedad se ven actualmente afectados por las graves consecuencias que provocan los delitos que merecen, según las leyes argentinas, penas privativas de la libertad y en particular los delitos de tráfico de armas, de personas, de órganos o tejidos y de estupefacientes, lavado de dinero, inversiones en actividades ilícitas, trata de personas, genocidio, crímenes de guerra, actos de terrorismo o delitos de lesa humanidad y de todo otro acto susceptible de ser juzgado por la Corte Penal Internacional (DNU 70/2017).

Es decir, subyace, a este diagnóstico, la idea de la necesidad de fortalecer las fronteras, ya que el control y la restricción del ingreso de los extranjeros al territorio es pensado como una solución para detener los flagelos sociales antes mencionados; es así que se instala una idea de "emergencia" en relación al fenómeno migratorio. Ahora bien,

La producción social de la emergencia ha sido un recurso habitual de la política moderna de cara a la intensificación del control social y la legitimación de medios excepcionales creados para afrontarla. Para poder funcionar, dicha producción necesita generar un cierto clima de pánico difuso frente a un fenómeno presentado como peligroso y potencialmente destructivo, así como la percepción de un determinado grupo social como enemigo (Zamora, 2005: 61).

En este sentido, el migrante aparece como una figura siempre posible de ser "usada" como potencial enemigo. Aun más, su calidad de "innombrable", dirá Bauman (1996) lo coloca en la posición de no ser ni amigo ni enemigo y es esta ambigüedad la que permite que, dadas ciertas circunstancias, sea colocado en la posición de generador de posibles riesgos para los nativos. En el DNU, los extranjeros son asociados con diversos "males" que aquejan a la sociedad, problemáticas que al no ser resueltas por el Estado son generadoras de aquel pánico difuso del que nos habla Zamora y, en dicha situación, el recurso del extranjero como "chivo emisario" resulta fácil de instalar.

Consecuentemente, al utilizar como fundamento este catálogo de delitos para el dictado de un decreto que modifica la ley migratoria, las representaciones sociales que naturalizan prejuicios e imaginarios sobre la otredad migrante, establecen una relación directa entre las migraciones y aquellos "peligros" que atentan a la "seguridad pública". Con este fin, en el DNU se citan estadísticas descontextualizadas e interpretadas de modo incorrecto provenientes del Servicio Penitenciario Federal. Son varios ya los autores que han sostenido que "las estadísticas policiales, judiciales y penitenciarias no pueden considerarse como fiel reflejo de la criminalidad que se ha producido, sino que más bien muestran la actividad de las distintas instancias del sistema penal" (Monclús Masó, 2016: 161): es decir, aquello que dicho sistema persigue y a quiénes fundamentalmente castiga. De esta manera, recurriendo a una información de este tipo 
para fundamentar una política criminalizante hacia los extranjeros, se refuerzan los prejuicios y estigmas que ya pesan sobre ciertas colectividades de migrantes en nuestro país, robusteciendo asimismo la idea de crisis y alarma.

En suma, la migración es pensada, una vez más, como un problema de "seguridad" para luego justificar que sea objeto de gestión represiva, es decir, de medidas que persiguen a los extranjeros y de políticas migratorias esencialmente restrictivas y excluyentes de los migrantes. Esa operación discursiva, que luego se vuelve operativa y traducida en prácticas concretas para combatir la situación de urgencia se evidencia también en el texto del DNU 70/2017.

Que la situación reseñada precedentemente justifica la regulación inmediata de un procedimiento migratorio especial de carácter sumarísimo, aplicable a aquellos casos en los que las personas de nacionalidad extranjera se encontraran involucradas en hechos delictivos $\mathrm{y}$ a quienes hubieren ingresado en forma clandestina al territorio nacional, eludiendo el control migratorio (DNU 70/2017).

Recapitulando, las modificaciones al texto original de la Ley, que se materializan en los 30 artículos que el DNU contiene y que suponen cambios sustanciales, podemos mencionar: la reducción de 30 a 3 días a partir de la notificación al migrante de la orden de expulsión para presentar un recurso de revisión; la eliminación del efecto suspensivo del trámite de expulsión mientras dure el proceso de revisión; el debilitamiento del derecho a la defensa al establecerse un sistema de expulsión express con tiempos imposibles de cumplirse; la posibilidad de que el migrante sea detenido en cualquier momento del procedimiento aunque la expulsión no esté firme; la denegación para todos los migrantes, tengan o no residencia, condenados o con procesamiento por delitos con pena privativa de libertad, aun aquellos de cumplimiento condicional; la cancelación de la residencia para migrantes condenados aunque la condena no esté firme, entre otros cambios; todos ellos criminalizan la migración al tiempo que iguala la condición de irregularidad migratoria (falta administrativa) con un delito.

En suma, si bien al momento de escritura de estas páginas, las consecuencias de estas modificaciones no han podido evaluarse de manera integral, es plausible prever que el DNU reinstala con virulencia la asociación entre migración y delito, que se plasma en disposiciones cuyo principal objetivo es el de ejercer el control sobre determinada población extranjera considerada como "grupo social potencialmente desviado" (De Giorgi, 2005). Así, coincidimos con Ceriani (2017: s/p) cuando dice que "... es posible afirmar que el DNU (en sus considerandos y en los discursos que acompañaron su presentación) viene a convertir una xenofobia latente en nuestra sociedad en política de Estado...".

\section{Conclusiones}

En el recorrido comparativo de las leyes en relación al sujeto migrante, notamos que en todas se construye un inmigrante deseable. Si bien las dos primeras leyes migratorias coinciden en convocar al inmigrante europeo lo hacen basadas en distintas apelaciones. Mientras la Ley Avellaneda pensó en lo que los migrantes podían aportar al desarrollo económico del país, la ley de la dictadura prefirió entender que eran portadores de una cultura que se integraba con la nacional, convirtiendo así a los migrantes limítrofes en los nuevos indeseables. Dada la permanencia de esta ley durante los primeros gobiernos democráticos que siguieron a la dictadura militar, en los años de auge neoliberal los inmigrantes limítrofes fueron confinados al lugar de ser los responsables de los problemas sociales que el propio modelo económico originaba. Así, el desempleo, la retracción del Estado como garante de derechos fundamentales como la educación, la salud y el acceso a la justicia fueron atribuidos, desde las representaciones sociales hegemónicas de la época, 
como una responsabilidad del inmigrante limítrofe.

Si bien, la idea de control migratorio por parte del Estado subyace en las tres normativas, éste ha seguido diferentes estrategias. Cierto es que la falta de documentación migratoria por parte del inmigrante pasó de convertirlo en ilegal (en el marco de la ley de la dictadura) a irregular (bajo la ley de migraciones 25871); no obstante, este status siguió dejándolo en los márgenes de la legalidad. En dicha ley, aún con importantes elementos progresistas en la concepción de las migraciones, el Estado quedó inmerso en lo que se conoce como la preocupación por la gobernabilidad migratoria. Así, "el aparato estatal empezó a prestar mayor atención al control de las fronteras y a validar la división entre nacionales y extranjeros a partir de criterios jurídico-políticos de exclusión asentados en el estatuto legal del inmigrante" (Domenech, 2011: 33). Domenech (2011) califica a este proceso como "la construcción legal de la ilegalidad" teniendo como una de sus mayores consecuencias el hecho de que la política migratoria quedara reducida a medidas de regularización y que nuevamente el sujeto migrante fuera construido como una amenaza al orden social que el Estado busca regular.

Asumir que el inmigrante es igual a un nacional es algo que aparece formalmente de manera contundente en la letra de la ley 25871, pero que sin embargo, se diluye en las representaciones y actos de los nacionales para con él. Así, paradójicamente, las leyes pueden incorporar y reconocer derechos (aunque siempre el Estado mantiene su rol de gestor de las migraciones y no resigna su poder soberano al respecto), mientras que las representaciones resultan ser bastante más estáticas e inmutables. Es por ello que resulta ineludible un análisis histórico amplio para identificar cuáles son los elementos discursivos que han constituido a la figura migrante en nuestro país. En consecuencia, resulta evidente que no basta con modificar la ley, pues ésta parece recorrer un camino, pero las representaciones sobre los migrantes otro, a veces, casi sin enterarse del cambio. En este sentido, es claro que los imaginarios y las prácticas se consolidan y sedimentan, por lo cual su viraje, en el sentido que marca una ley, al menos en un corto plazo, resulta cuando menos, dificultoso. En síntesis, "hay una gran brecha entre el fenómeno fáctico de la migración, la manera como éste se percibe y las respuestas que se construyen para enfrentarlo por parte de las instituciones, las sociedades de origen y recepción y los mismos sujetos migrantes" (Villa Martínez, 2011, pág. 341). Acerca de este punto, debe reconocerse que no colaboró en la readaptación a la nueva ley el lapso transcurrido entre la sanción y su reglamentación (siete largos años), en el que no sólo los nativos sino los funcionarios del Estado se hallaban en un limbo en el que, "ante la duda", siguieron aplicando la ley de la dictadura.

Todo ello se agrava en la actualidad con la sanción del Decreto de Necesidad y Urgencia 70/2017, al tiempo que, la escasa resistencia que ha tenido el mismo en el seno de la sociedad argentina, nos demuestra que las representaciones sociales, como las que hemos reseñado y que construyen al migrante como un "problema", persisten y resurgen con virulencia frente a un nuevo contexto marcado por el cambio de signo político de gobierno.

\section{Bibliografía}

Bauman, Z. (1996): "Modernidad y ambivalencia", en Giddens, N. , N. Luhmann y U. Beck, comps., Las consecuencias perversas de la modernidad, Barcelona, Ed. Anthropos, pp. 73-119.

Carril, C (2017): Informe Técnico DNU 70/17. Disponible en web: http://www.defensoria.org. ar/wp-content/uploads/2017/03/INFORME-T\%C3\%89CNICO-DNU.pdf [Consulta: 10 de septiembre de 2017]

Cascone, A (2017): Inconstitucionalidad de la modificación del artículo 86 de la ley $\mathrm{N}^{\mathrm{o}} 25.871$ a través del DNU 70/17. Disponible en web: $\underline{\text { https:// }}$ jurisprudencia.mpd.gov.ar/Estudios/2017.4.\%20 
Inconstitucionalidad\%20de\%201a\%20modificaci\%C3\%B3n\%20de1\%20art.\%2086\%20de\%20 la\%201ey\%2025.871.pdf [Consulta: 15 de octubre de 2017]

Ceriani Cernadas, P. (2017): Dictamen Técnico sobre DNU 70/2017 que reformó la Ley de Migraciones 25.871. Disponible en web: http:// iarpidi.org/2017/03/24/dictamen-tecnico-sobreel-dnu-702017-que-reformo-la-ley-de-migraciones-25-871/ [Consulta: 15 de octubre de 2017]

Crosby, A. (2006): "Las fronteras de la pertenencia: reflexiones sobre las políticas de migración. Entrando al siglo XXI", InterPares, 7, pp. 1-16.

De Giorgi, A. (2005): Tolerancia Cero: estrategias y prácticas de la sociedad de control, Roma, Virus Editorial.

Domenech, E. (2011): "Crónica de una 'amenaza' anunciada. Inmigración e 'ilegalidad': visiones de Estado en la Argentina contemporánea", en Feldman-Bianco B., L. Rivera Sánchez, C. Stefoni, \& M. Villa Martínez, comps., La construcción social del sujeto migrante en América Latina: prácticas, representaciones y categorías, Quito, CLACSO, pp.31-77.

Feldman-Bianco, B. (2011): "Introducción", en Feldman-Bianco, B., L. Rivera Sánchez, C. Stefoni, \& M. I. Villa Martínez, comps., La construcción social del sujeto migrante en América Latina. Prácticas, representaciones y categorías, Buenos Aires, CLACSO, pp. 15-27.

Jodelet, D. (1986): "La representación social: fenómenos, concepto y teoría”, en S. Moscovici, Psicología social, Barcelona, Paidós, pp. 469494.
Monclús Masó, M. (2006): "La discriminación de los inmigrantes en el sistema penal español", en Bergalli, B., comp., Flujos migratorios y su descontrol: puntos de vista pluridisciplinarios, Barcelona, Anthropos, pp. 159-200.

Novick, S. (2014): Cómo trabajar con textos jurídicos en Ciencias Sociales, Buenos Aires, Documento de trabajo $N^{\circ} 69$, Instituto de Investigaciones Gino Germani.

Novick, S. (2008): "Migración y políticas en Argentina: tres leyes para un país extenso (18762004)", en S. Novick, Las migraciones en América Latina. Políticas, cultura y estrategias, Buenos Aires, Catálogos-CLACSO.

Novick, S. (2005): Evolución reciente de la política migratoria argentina, Buenos Aires, Instituto de Investigaciones Gino Germani. Disponible en: http://webiigg.sociales.uba.ar/pobmigra/archivos/iussp.pdf [Consulta: 18 de diciembre de 2017]

Strauss, A., \& J. Corbin (2002): Bases de la investigación cualitativa. Técnicas y procedimientos para desarrollar la teoría fundamentada, Bogotá, CONTUS-Editorial Universidad de Antioquia.

Velasco, J. C. (2016): El azar de las fronteras. Políticas migratorias, ciudadanía y justicia, México, FCE.

Villa Martínez, M. I. (2011): Desplazados y refugiados: entre ser, merecer y ocultar su situación. A propósito de la migración forzada de colombianos en Colombia, Ecuador y Canadá", en Feldman-Bianco, B., L. Rivera Sánchez, C. Stefoni, \& M. I. Villa Martínez, comps., La construcción social del sujeto migrante en América Latina. Prácticas, representaciones y categorías, 
Quito, FLACSO, pp. 339-366.

Zamora, J. (2005): "Políticas de inmigración, ciudadanía y estado de excepción", ARBOR. Ciencia, pensamiento y cultura, 181, pp. 53-66.

\section{Legislaciones citadas:}

DNU 70/2017. Modificación Ley número 25.871. Disponible en web: https://www.boletinoficial. gob.ar/\#!DetalleNorma/158336/20170130 [Consulta: 15 de octubre de 2017]

Ley de Migraciones 25871. Disponible en web: http://servicios.infoleg.gob.ar/infolegInternet/ anexos/90000-94999/92016/texact.htm [Consulta: 15 de octubre de 2017]

Ley "Videla", Ley general de Migraciones y fomento de la inmigración ley 22.439/81. Disponible en web: http://valijainmigracion.educ.ar/ contenido/materiales para formacion docente/ textos de consulta/19\%20Ley\%20Videla\%20 $22439 \% 20$ de $\% 20$ migraciones $\% 20 y \% 20$ fomento $\% 20 \mathrm{de} \% 201 \mathrm{a} \% 20 \mathrm{inmigracion} . \mathrm{pdf}$ [Consulta: 15 de octubre de 2017]

Ley "Avellaneda" 817. Disponible en web: http://campus.filo.uba.ar/mod/resource/view. php?id=34211 [Consulta: 15 de octubre de 2017]

Recibido: 30 de octubre de 2017

Aceptado: 05 de enero de 2018

\section{NOTAS}

[1] Las mismas fueron realizadas durante los años 2011-2014 en el marco del Proyecto de investigación UBACyT "Diversidad etno-nacional y construcción de desigualdades en las instituciones escolar y judicial. Un desafío teórico-metodológico en el abordaje de los casos del AMBA y la provincia de Mendoza", del que las autoras participamos, en calidad de becarias y tesistas, en la realización del trabajo de campo.

[2] El material producido en el marco del trabajo de campo ha sido procesado con criterios cualitativos mediante la confección de grillas en las que, inicialmente, se realizó una codificación abierta según la metodología de Strauss y Corbin (2002) para estimular el descubrimiento de categorías, propiedades y dimensiones de análisis. Luego se implementó una codificación axial en la que se procedió a la comparación continua de los datos. Finalmente, la codificación selectiva entre dimensiones buscó la reducción de categorías, facilitando el entrelazamiento de codificación-grillado, análisis de contenido de los discursos e interpretación de la información obtenida.

[3] Establecía que cualquier extranjero podía ser expulsado si el mismo comprometía la "seguridad nacional" o perturbaba el "orden público". Ello suponía que el Poder Ejecutivo podía expulsar o negar el ingreso a los extranjeros que consideraba "peligrosos" a partir de un criterio arbitrario y poco claro.

[4] Otorgándole también potestades al Poder Ejecutivo, tales como las de detener a personas consideradas un peligro para el "orden público", prohibía la entrada de anarquistas, suspendía la libertad de imprenta, el derecho de reunión, de asociación y de manifestación. 
[5] Diccionario de la Real Academia Española. Recuperado de: http://dle.rae.es/?id=HA2OTXGlHA2tbn5 [Consulta: 20 de mayo de 2017]

[6] Por ejemplo, ver el artículo 29 de la Ley 25871, donde se especifican las "causas impedientes del ingreso y permanencia de extranjeros en territorio nacional."

[7] Art. 98, Ley 25.871.

[8] Art. 120 de la Constitución de la Nación Argentina.

[9] Disponible en: http://www.mpd.gov.ar/articulo/index/articulo/creacion-integracion-98 [Consulta: 20 de mayo de 2016]

[10] "El Ministerio Público de la Defensa es la institución encargada de asegurar la efectiva asistencia y defensa judicial de los derechos de las personas. El servicio es brindado por los defensores públicos, tutores y curadores públicos, que integran el organismo, a nivel nacional, en el ámbito de la Capital Federal, y a nivel federal, en todo el país. A partir de la reforma constitucional del año 1994, el Ministerio Público de la Defensa se instituye como un órgano independiente del resto de los Poderes del Estado, con autonomía funcional y autarquía financiera (art. 120 Constitución Nacional). De acuerdo al nuevo mandato constitucional, el Ministerio Público de la Nación se concibió como un órgano expresamente previsto en el texto constitucional y bicéfalo, en tanto cuenta con dos estructuras autónomas e independientes entre sí: el Ministerio Público Fiscal, integrado por el procurador general de la Nación, como su jefe máximo, y los fiscales; y el Ministerio Público de la Defensa, compuesto por los defensores, tutores y curadores públicos, cuya máxima autoridad es el defensor general de la Nación.

Con anterioridad a la reforma, los defensores públicos se encontraban dentro de la estructura del Poder Judicial y dependían funcionalmente de la Corte Suprema de Justicia de la Nación, operando esta circunstancia en desmedro de la garantía de igualdad entre las partes y del derecho a una tutela efectiva de los derechos de los justiciables. El cambio institucional producido representó, entonces, un importante avance para el fortalecimiento de la defensa pública en tanto actor protagónico dentro del sistema de justicia para la firme protección de los derechos de las personas". (Texto extraído de la página web del Ministerio Público de Defensa, donde también puede encontrarse la Ley Orgánica del Ministerio Público Disponible en: http://www.mpd.gov.ar/institucional). [Consulta: 20 de marzo de 2015]

[11] La entrevistada refiere al Programa Patria Grande (no fue una Ley, sino que éste colaboró en el diagnóstico de la situación para la posterior redacción de aquella), lanzado por Decreto en el año 2004 e implementado en el 2005, que tuvo como objetivo regularizar la situación migratoria de miles sujetos provenientes de Sudamérica, en especial, de aquellos países que en aquel momento integraban el MERCOSUR. Los resultados de dicha regularización, pueden consultarse en: http://www.migraciones.gov.ar/pdf_varios/ estadisticas/Patria_Grande.pdf [Consulta: 10 de octubre de 2017]

[12] Disponible en: http://www.defensoria. org.ar/wp-content/uploads/2017/03/INFORME-TÉCNICO-DNU.pdf [Consulta: 10 de septiembre de 2017]

[13] Ver documento disponible en: https://jurisprudencia.mpd.gov.ar/Estudios/2017.4.\%20 Inconstitucionalidad $\% 20 \mathrm{de} \% 201 \mathrm{a} \% 20$ modificación\%20del\%20art.\%2086\%20de\%201a\%20 ley\%2025.871.pdf [Consulta: 15 de octubre de 2017] 